\title{
Study on the Influence of Online Merchandise Display on Consumer Product Quality Perception-The Mediating Role of Virtual Tactility
}

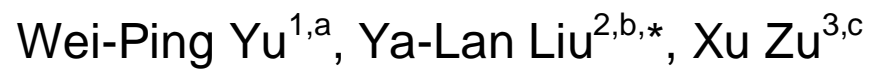 \\ ${ }^{1,2,3}$ Business School of Sichuan University, Chengdu in China \\ a331382107@qq.com, b1208141947@qq.com, '403008983@qq.com \\ ${ }^{*}$ Corresponding author
}

Keywords: Virtual tactility, Product quality perception, Model display, Fabric swatch, Time distance.

\begin{abstract}
Based on 2 empirical studies, we explore the influence of two kinds of online clothing presentation manner--"model display" and "fabric swatch presentation" on consumer product quality perception from the virtual tactile perspective, and examine the moderating effect of time distance. In study 1 , we show that model display can significantly influence and improve the virtual tactility and product quality perception; in study2, we show that the effect of fabric swatch presentation on virtual tactility and product quality perception is also significant, when there is fabric swatch presentation, the virtual tactility and product quality perception are stronger. In both studies, virtual tactility acts as a complete mediate variable, and time distance plays a moderating role in the effect which virtual tactility have on product quality perception.
\end{abstract}

\section{Introduction}

According to Chinese online shopping market data in 2014, online shopping market transactions reached 2.8 trillion, which has increased by $48.7 \%$ in china. In such a large network shopping sales, the proportion of apparel sales are the largest. Previous studies have found that for experiential goods such as clothing, cosmetics, Consumers' tactile experience plays a crucial role in the purchase decision process [1]. However, it is difficult to provide the real tactile experience to consumers in network shopping environment. Happily, with the rapid development of internet technology, more and more online retail enterprises have been adopting diversified content for merchandise display, in order to compensate for the lack of consumers' tactile perception.

Taking women's clothing in Tmall as an example, usually the clothing display contents cover: "product parameters", "Model display ","product figure ", and "size and try ". Among them the most popular display content is the "Model shows ". In addition, we find a few merchants also use the merchandise fabric swatch as presentation content. So, for the most popular display content "model display ", may it affect or increase the virtual touch perception of consumers, or may it affect consumers' perception of the product's quality? Besides, for the fabric swatch which is rarely used in clothing presentation, whether it won't affect the virtual touch perception or the product quality perception of consumers? These questions are worth exploring.

From the previous relevant studies, researchers have found that model display is the best in apparel retail websites. Because model display is mostly close to the consumer perception, so it will bring consumers the best virtual experience[2].Also some researchers find that many apparel retail websites provide fabric swatch and color swatch to help consumers evaluate merchandise and get better virtual experience [3]. It is no hard to find in these studies, the researchers mainly focus on the influence which the online clothing display have on consumers' virtual experience .But for virtual tactility, can model display and fabric swatch presentation help consumers to form virtual tactility indeed? Or whether this virtual tactility has influence on consumers' product quality perception? No researchers give a clear answer. In addition, some psychological variables have not yet been introduced into the related research currently. For the effect which the virtual tactility has on consumers' product quality perception, whether there is a time boundary? Or whether the difference of time distance can influence the mechanism of this effect? To answer these questions, 
"time distance" will be introduced to the conceptual model in this study.

\section{Literature Review}

\section{Online Merchandise Displaying}

Online merchandise display is a multi-dimensional concept, khakimd janova(2005) etc consider that we should learn commodities display manners from 5 dimensions, including: display technology, Supplementary display, display aesthetic ,display structure and layout[4]; Ha, Kwon and Lennon (2007)[5] put forward six manners of product presentation when they inspect presentation manners of commodities on clothing retail websites, including types of product view (look forward, back and side ), presentation methods (click properties, automatic rotation), detailed views (2D or 3D picture, features and zoom functions), swatch (fabric swatch, color swatch), color presentation (change color, color contrast figure), product display method (suspension, tile, mannequins, reality fitting), mix and match. Many researchers find that, virtual technology can help consumers to form virtual tactility of products in the online shopping environment, and it will help consumers to evaluate the quality of merchandise and make a purchase decision.

\section{Virtual Tactility}

In online shopping website, some virtual technology can compensate for the lacking of touch experience to some extent. Especially, consumers' presence perception and multi-sensory compensation mechanism generated by online shopping will make the consumers feel that they touch the merchandise actually, researchers call it virtual tactility. Reb etc (2007) [6] find that touch can change consumers' attitudes and behaviors, Grohmann etc (2007) [7] point out the tactile elements of goods or services play an important role in the consumer's purchase decision. Liu Shengnan etc (2011) [ 8 ] have used the cognition theory and multi- sensory interaction and integration theory to explain the formation of virtual tactility and compensation mechanism. Chylinski (2011) [9]point out that the interaction of commodity factors, individual factors and shopping environment affects the formation of consumer virtual tactility.

\section{Product Quality Perception}

Zeithaml (1988) [10] defines perceived product quality as the subjective evaluation and judgment of the product's quality. Holbrook and Corfman (1985) [11] divide the definition of perceived value into three levels: 1. a kind of subjective judgment and evaluation of consumers; 2. obvious subjectivity determining the differences of consumers' perceptions for the same product; 3 . the consumer experience can affect their quality perception. Therefore, quality perception is a relative concept [12]. At the same time, due to the subjectivity of buying behaviors, the product quality perception is considered to be the direct factor which determines consumers' behaviors in a long period [13].

\section{Time Distance}

In definition of construal level theory, time distance refers to the individual perception of incident which happened far or near [14]. Time distance will shift the originally attention center of consumers [15].The time discounting theory considers that the estimated value of the event will changes regularity with the time distance [16]. This theory points out that longer time distance lead to less perceived value [17].

\section{Model and Hypothesis}

Our conceptual model is showed in Figure1. Then and Delong (1999) find in apparel websites, model display is the best, because it is mostly close to the daily life and perception of consumers, so it will bring consumers the best virtual experience [2]. Thus, we can infer that model display also can help consumers to evaluate the quality of product, and put forward the following hypotheses:

H1: Model display of online clothing has a positive effect on virtual tactility. 
H2: Model display of online clothing has a positive effect on product quality perception.

Merchandise' physical attributes are important factors influencing consumers' tactile perception and tactile experience. Weber (1978) considers that if the materials of goods have differences in tactile properties, consumers' tactile perception and experience can be affected [18]. Lennon and Kim (2006) also find that many apparel shopping websites provide fabric swatch and color swatch to help consumers evaluate goods and get better virtual experience [3]. On this basis, we propose the following hypotheses:

H3: Fabric swatch presentation of online clothing has a positive effect on virtual tactility.

H4: Fabric swatch presentation of online clothing has a positive effect on product quality perception.

For $\mathrm{S}-\mathrm{O}$ - R theory it considers that the shopping environment $(\mathrm{S})$ will affect consumers' psychological state (O), and then affects consumers' attitudes and behaviors (R). Peck (2003) [19] think that touch can improve consumer's attitude, and improve the product's evaluation, enhance their purchase intention. Thus, we hypothesize the following:

H5: Virtual tactility has a significant positive effect on product quality perception;

Peck and Childers (2003)[19]find that providing product tactile information (such as a sweater of softness, composition) to consumers whose need for touch is high can compensate for the shortage of touching products .so as to enhance their confidence in the product's quality. On this basis, we can infer that model display and fabric swatch presentation can help consumers get products' virtual tactility in the network shopping environment, so as to evaluate the quality of products. Therefore, we put forward the following hypotheses:

H6: Virtual tactility plays a mediating role in the effect of model display on product quality perception.

H7: Virtual tactility plays a mediating role in the effect of fabric swatch presentation on product quality perception.

In construal level theory, it is thought that the construal level depends on the level of people's perception and cognition of the object, thereby affecting people's judgment and decision-making. Malkoc and Zauberman (2008) [20] consider that more time distance will lead to less value perception, on this basis, we put forward the following hypotheses:

H8: When time distance is short, virtual tactility has more positive effect on consumer product quality perception;

H9: When time distance is long, virtual tactility has less positive effect on consumer product quality perception.

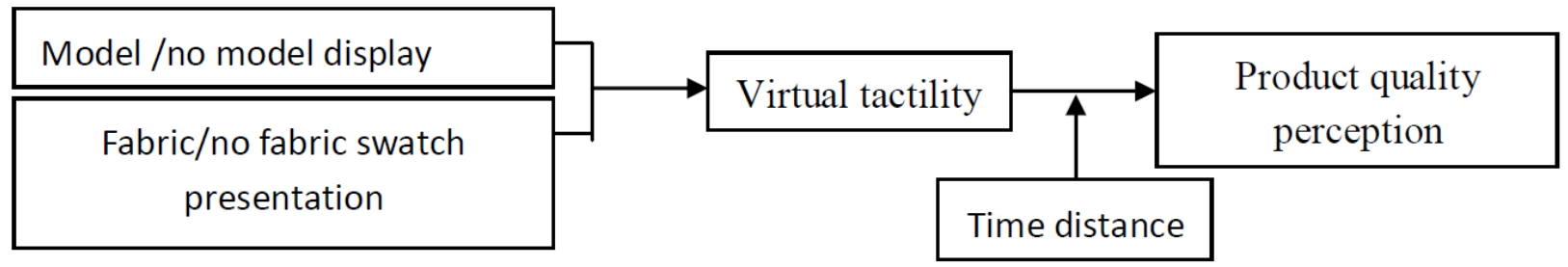

Fig. 1 The Conceptual Model

\section{Study 1}

The purpose of study 1 was to test $\mathrm{H} 1-\mathrm{H} 2, \mathrm{H} 5-\mathrm{H} 6, \mathrm{H} 8-\mathrm{H} 9$ and to determine the influence of model display on consumer product quality perception as well as the mediating role of virtual touch tactility. Study 1 was a 2 (model display /no model display) x 2 (long time distance/ short time distance) design.

\section{Procedure and Variables}

165 college students from a university in China were selected to participate in the experiment. 93 percents of the participants had three years internet age, and $100 \%$ of the participants had online clothing shopping experience. Eliminate invalid questionnaires, the actual number of participants 
was 144 (male 62, female 82).

Referred the previous related studies [21], we selected the biggest-selling woolen sweater as a stimulant from Tmall website.

Participants were randomly assigned to four groups: 2(model /no model display) x 2(long /short time distance). At the beginning, they were asked to imagine that they need to buy a woolen sweater to keep warm. Then the participants in each group would view the woolen sweater display pictures of their group. After viewing pictures they should finish the measurement scale.

We manipulated model /no model display by varying the picture on which the sweater was displayed by model or without model, at the same time; we controlled the model's motion and expression, background, size and color of the clothes. Besides, we manipulated long/short time distance by varying time in formation; two groups of participants were told to imagine buying a woolen sweater tomorrow and the other two groups of participants were told to imagine buying a woolen sweater after two months. Results showed that the time distance was successfully manipulated $(\mathrm{F}=17.727, \mathrm{p}=0.000<0.05)$.

We used degrees of softness, warmth, porosity and lightness [12] to measure the tactility of sweater. Reliability of scale was 0.80 . As for the measurement of product quality perception, we used 3 items which were from previous related research measurement [22,23]. And the reliability of scale was 0.94.

\section{Results}

With one-way analysis of variance, we found model/no model display had a significant effect on virtual tactility $(\mathrm{F}=3.533, \mathrm{p}<0.01)$, consumers' virtual tactility was higher when there was model display than that when there was no model display $\left(\mathrm{M}_{\text {model }}\right.$ display $=5.2950 \mathrm{vs} \mathrm{M}_{\text {no model display }}=4.0938$, $\mathrm{p}<0.01) \mathrm{H} 1$ was verified. At the same time, we found model/no model display had a significant effect on product quality perception $(\mathrm{F}=2.318, \mathrm{p}<0.01)$, consumers' product quality perception was higher when there was model display than that when there was no model display $\left(\mathrm{M}_{\text {model }}\right.$ display $\left.=4.2174 \mathrm{vs} \mathrm{M}_{\text {no model display }}=3.3406, \mathrm{p}=0.000\right) \mathrm{H} 2$ was verified.

With virtual tactility as the independent variables, product quality perception as the dependent variable, we did linear regression analysis. The results showed that virtual tactility had a positive effect on product quality perception $(\beta=0.575, \mathrm{p}=0.000<0.05)$, and $\mathrm{H} 5$ was verified.

Using the test method of mediation effect [24], we found that model display had a positive effect on product quality perception before we put virtual tactility to the regression model $(\beta=0.500$, $\mathrm{p}=0.000<0.05$ ), And then the effect became not significant after we put virtual tactility to the regression model $(\beta=0.141, p=0.112>0.05)$, and virtual tactility had a significantly positive effect on product quality perception $(\beta=0.505 \mathrm{p}=0.000<0.05)$. Thus virtual tactility had a complete mediation effect, and H6 was confirmed.

Through group regression analysis, we found that time distance played a negative moderating role in the effect which virtual tactility had on product quality perception. As shown in Table 1, shorter distance led to higher product quality perception and longer distance lead to lower product quality perception. $\mathrm{H} 8$ and $\mathrm{H} 9$ were verified.

Tab. 1 Moderating Effect Analysis Results

\begin{tabular}{|l|c|c|c|c|c|c|}
\hline & \multicolumn{3}{|c|}{ Long time distance } & \multicolumn{3}{c|}{ Short time distance } \\
\hline & Beta & $\mathrm{T}$ & Sig & Beta & T & Sig \\
\hline virtual tactility & .508 & 6.573 & .000 & .549 & 4.118 & .000 \\
\hline
\end{tabular}

\section{Study 2}

The purpose of study 2 is to test $\mathrm{H} 3-\mathrm{H} 5, \mathrm{H} 7-\mathrm{H} 9$, and to determine the influence of fabric swatch presentation on consumer product quality perception as well as the mediating role of virtual touch tactility. Study 2 was a 2 (fabric swatch presentation /no fabric swatch presentation) x 2 (long time distance /short time distance) design. 


\section{Procedure and Variables}

150 college students from a university in China were selected to participate in experiment $2.95 \%$ of the participants had three years Internet age, and $100 \%$ of the participants had online clothing shopping experience. Eliminate invalid questionnaire, the actual number of participants was 140 (male 68, female 72).

In experiment 2, we used the same stimulant, variables and procedure as experiment 1 .We manipulated fabric /no fabric swatch presentation by varying the picture to which we added fabric swatch besides the woolen sweater presentation or not. we manipulated time distance with the same way in experiment 1 , and results showed that the manipulation was successful $(\mathrm{F}=7.464$, $\mathrm{p}=0.007<0.05)$.

\section{Results}

With one-way analysis of variance, we found that fabric/no fabric swatch presentation had significant impact on virtual tactility $(\mathrm{F}=2.508, \mathrm{p}<0.01)$, consumers' virtual tactility was higher when there is fabric swatch presentation than that when there was no swatch presentation( $\mathrm{M}_{\text {fabric }}$ swatch presentation $=5.2950 \mathrm{vs} \mathrm{M}$ no fabric swatch presentation=4.0938, $\mathrm{p}<0.01) \mathrm{H} 3$ was verified. At the same time, we found fabric/no fabric swatch presentation had a significant effect on product quality perception $(\mathrm{F}=1.487, \mathrm{p}<0.01)$, consumers' product quality perception was higher when there is fabric swatch presentation than that when there was no swatch presentation( $M$ fabric swatch presentation $\left.=4.4203 \mathrm{vs} \mathrm{M}_{\text {no fabric swatch presentation }}=3.6042, \mathrm{p}<0.01\right) \mathrm{H} 4$ was verified.

With virtual tactility as the independent variables, product quality perception as the dependent variable, we did linear regression analysis. The results showed that virtual tactility had a positive effect on product quality perception $(\beta=0.573, \mathrm{p}=0.000<0.05)$ so the. H5 was verified.

Using the test method of mediation effect[24], we found that fabric swatch presentation had a positive effect on product quality perception before putting virtual tactility to the regression model $(\beta=0.358, p=0.004<0.05)$, and then the effect became not significant after putting virtual tactility to the regression model $(\beta=0.087, \mathrm{p}=0.526>0.05)$. and virtual tactility had a significantly positive effect on product quality perception $(\beta=0.466 \mathrm{p}=0.001<0.05)$. Thus virtual tactility had a complete mediation effect, so $\mathrm{H} 7$ was confirmed.

Virtual tactility as the independent variables, product quality perception as the dependent variable, we did group regression analysis. The results were showed in table 2 . Time distance played a moderating role in the effect which virtual tactility had on product quality perception, the shorter time distance, the higher product quality perception; the longer time distance, the lower product quality perception. $\mathrm{H} 8$ and $\mathrm{H} 9$ were verified again.

Tab. 2 Moderating Effect Analysis Results

\begin{tabular}{|l|c|c|c|c|c|c|}
\hline & \multicolumn{3}{|c|}{ Long time distance } & \multicolumn{3}{c|}{ Short time distance } \\
\hline & Beta & $\mathrm{T}$ & $\mathrm{Sig}$ & Beta & $\mathrm{T}$ & Sig \\
\hline virtual tactility & .468 & 3.329 & .002 & .667 & 3.255 & .004 \\
\hline
\end{tabular}

\section{Conclusions and Discussion}

Different from previous research, we explored the influence of online clothing display on consumer product quality perception from the virtual tactile perspective. Through summarizing online commodity display dimensions in literature and the product display content used by appeal web sites, we chose two dimensions" model display" and" fabric swatch presentation" as the independent variable, and designed two experiments to do this study, refining the division of online merchandise display in previous related studies .The conclusions showed that model display and fabric swatch presentation could significantly influence and improve the virtual tactility and product quality perception; secondly, virtual tactility could significantly influence consumers' product quality perception, and virtual tactility acted as a complete mediate variable between online clothing 
presentation and product quality perception. So for some costume merchandise whose tactile information is important, such as wool, silk dresses, the online merchants should use model display as far as possible and add fabric swatch presentation to improve consumers' virtual tactility as well as the product quality perception. Finally, the study found that time distance played a negative moderating role in the effect which virtual tactility had on product quality perception. When time distance was short, virtual tactility had a stronger effect on product quality perception. Therefore, if online merchants want to do pre-sale or counter-season clothing sale, they should pay more attention to virtual tactile stimulation, avoiding consumers' product quality perception be reduced, so as to realize the clothing sales increasing.

\section{Limitations}

First, in this study, we only chose women's appeal as the research object, thus some of the conclusions may not be applicable to other product categories .Future researches may need to expand the product categories .Secondly, the participants of the two experiments in this study were college students, mainly 20 to 30 years old, the diversification of the sample was not enough. Third, the experimental environment of this study was not the same as the real network shopping environment, future research need to improve the experimental environment. Finally, this study only researched the tactile senses; the following studies can consider the influence of multi-sensory interaction on consumers' attitudes and behaviors.

\section{Reference}

[1] ROSA, GARBARINO, MALTER. Keeping the body inmind: the influence of body esteem and body boundary aberration on consumer beliefs and purchase intentions[J].Journal of consumer psychology,2006, 16(1) : 79-91.

[2] By Then, Nicole K.; DeLong, Marilyn R. Apparel Shopping on the Web[J]. Journal of Family and Consumer Sciences, Vol. 91, No. 3 , January 1, 1999.

[3] Kim M, Kim J, Lennon S J. Online service attributes available on apparel retail web sites: an E-S-QUAL approach[J]. Managing Service Quality An International Journal, 2006.

[4] Khakimdjanova L, Park J. Online visual merchandising practice of apparel e-merchants[J]. Journal of Retailing \& Consumer Services, 2005, 12(5):307-318.

[5] Ha Y, Kwon W, Lennon S J. Online visual merchandising (VMD) of apparel web sites[J]. Journal of Fashion Marketing \& Management An International Journal, 1996, volume 11(4):477-493(17).

[6] J. REB, T. Connolly. Possession, Feelings of Ownership, and the Endowment Effect[J] Judgment and Decision Making,2007,2(2):107 114.

[7] Grohmann B, Spangenberg E R, Sprott D E. The influence of tactile input on the evaluation of retail product offerings[J]. Journal of Retailing, 2007, 83(2):237-245.

[8] Liu Shengnan da-hai dong. The understanding of the online shopping consumer virtual experience based on two psychological theory to $[\mathrm{J}]$. Journal of foreign economy and management, 2011, (2):41-47.

[9] Chylinski M. Sensory marketing: research on the sensuality of products, Aradhna Krishna. Routledge, New York (2010).[J]. Journal of Economic Psychology, 2011, (5):832-833.

[10] Zeithaml V A, Berry L L, Parasuraman A. Communication and control processes in the delivery of service quality[J]. Journal of Marketing, 1988, 52(2):35-48.

[11] Holbrook, M.B. \& Corfman, K.P. (1985). Quality and value in the consumption experience: Phaedrus rides again, In Jacoby, J. and Olson, J., (Eds.), Perceived quality, Lexington, MA: 
Lexington Books, 31-57.

[12] Bar-Anan Y, Liberman N, Trope Y, et al. Automatic processing of psychological distance: Evidence from a Stroop task[C]. //Journal of Experimental Psychology General. 2007:610--622.

[13] Zeithaml, Valarie. A., Leonard. L. Berry and A. Parasuraman (1996), "The Behavioral Consequences.

[14] Liberman N, Trope Y, Stephan E. 15. Psychological distance[J]. Arie W Kruglanski, 2007:págs. 353-384.

[15] Zhao, M., Hoeffler, S., \& Zauberman, G. (2007). Mental simulation and preference consistency over time: The role of process-versus outcome-focused thoughts. Journal of Marketing Research, 44(3), 379-388.

[16] Loewenstein G, Read D, Baumeister R. Time and Decision: Economic and Psychological Perspectives on Intertemporal Choice[J]. Journal of Economic Literature, 2003, 64(3):419-422.

[17] Loewenstein G, O'Donoghue T, Rabin M. PROJECTION BIAS IN PREDICTING FUTURE UTILITY[J]. Quarterly Journal of Economics, 2003, 118(4):1209-1248.

[18] Weber E H. The sense of touch[J]. Journal of general psychology, 1978.

[19] Peck J, Childers T L. To Have and To Hold: The Influence of Haptic Information on Product Judgments[J]. Journal of Marketing A Quarterly Publication of the American Marketing Association, 2003, 67(2):págs. 35-48.

[20] Zauberman G, Kim B K, Malkoc S A, et al. Discounting time and time discounting: Subjective time perception and intertemporal preferences[J]. Journal of Marketing Research, 2008, 46(4):543-556.

[21] M H, R F, S R, et al. Perceptual dimensions of tactile surface texture: A multidimensional scaling analysis[C]. //Perception \& Psychophysics. 1993:697-705.

[22] Fazio R H, Zanna M P. On the predictive validity of attitudes: The roles of direct experience and confidence1[J]. Journal of Personality, 1978, 46(2):228-243.

[23] M Eckman, ML Damhorst, SJ Kadolph. Toward a Model of the In-Store Purchase Decision Process: Consumer Use of Criteria for Evaluating Women's Apparel[J] Clothing and Textiles Research Journal January 1990 vol. 8 no. 2 13-22.

[24] Zhong-lin wen, zhang lei, kit-tai hau, etc. The inspection procedures of mediation effect of and its application [J]. Journal of psychology,2004, 36(5):614-620. 